\title{
Overstocking in the trans-Himalayan rangelands of India
}

\author{
CHARUDUTT MISHRA ${ }^{1,2}$, HERBERT H.T. PRINS ${ }^{1}$ AND SIPKE E. VAN WIEREN ${ }^{1 *}$ \\ ${ }^{1}$ Tropical Nature Conservation and Vertebrate Ecology Group, Department of Environmental Sciences, Wageningen University, Bornsesteeg 69, \\ 6708 PD Wageningen, The Netherlands, and ${ }^{2}$ Centre for Ecological Research and Conservation, 3076/5, IV Cross Gokulam Park, Mysore 570002, \\ India
}

Date submitted: 2 August 2000 Date accepted: 16 May 2001

\section{Summary}

High livestock densities in rangelands can result in reduced animal production due either to overgrazing or reduced per caput food availability, yet evidence for reduced animal production due to overstocking is scarce. Here simple animal production models establish the occurrence of overstocking in a traditional agropastoral system in the Spiti Valley of the Indian Trans-Himalaya. Empirical data show that fecundity of adult female livestock is related to total livestock biomass density $(S)$ as a negative linear function of $S$. Total herd production is modelled as a quadratic function of $S$, thereby calculating an optimum livestock biomass density $\left(S_{o p}\right)$, at which total herd production is maximized. A sample of 40 villages showed that over $83 \%$ of Spiti's rangelands may be overstocked with values of $S>S_{o p}$. Overstocking seems to be a classic case of the tragedy of the commons, as livestock is individually owned while the land is communally grazed. Recent socio-economic changes have probably contributed to high levels of overstocking. Even areas within wildlife reserves are overstocked. Conservation management needs to focus on creation of grazing free areas and management of livestock densities.

Keymords: rangelands, animal production, overgrazing, transHimalaya, India

\section{Introduction}

Maximizing sustained livestock production is the central concern of most livestock production systems as well as of range ecology. Pastoralists often maintain herds at high stocking density in order to maximize production. However, stocking more animals than can be adequately fed in the rangelands can actually compromise herd production, lead to rangeland degradation, and undermine conservation efforts in areas where livestock and wildlife share the rangelands. The Trans-Himalayan regions of the Tibetan Plateau and the Tibetan marginal mountains, spanning over 2.6 million $\mathrm{km}^{2}$, represent an ecosystem where most of the area has been

\footnotetext{
* Correspondence: Dr Sipke E. van Wieren Tel: +31 317483434 Fax: +31317484845 e-mail: sip.vanwieren@staf.ton.wau.nl
}

subject to traditional pastoralism and agro-pastoralism for several millennia (Handa 1994; Schaller 1998). The region also harbours a unique assemblage of wild herbivores, such as the wild yak (Bos grunniens), Tibetan antelope (Pantholops hodgsoni), Tibetan gazelle (Procapra picticaudata), Tibetan argali (Ovis ammon), ibex (Capra ibex), bharal (Pseudois nayaur), and associated predators such as the snow leopard (Uncia uncia). In Spiti Valley of the Indian Trans-Himalaya, livestock grazes the entire catchment, and, consequently, wild herbivores and livestock share the rangelands. We examine livestock stocking densities in the rangelands of Spiti, which includes area within Spiti's wildlife reserves, with the ultimate aim of guiding conservation management in the Trans-Himalaya.

Overgrazing is a worldwide concern, has been a subject of much deliberation, and yet conclusive evidence for its occurrence has been remarkably difficult to find. Indeed, changes in vegetation composition, dominance of unpalatable species, and areas of accelerated erosion in rangelands are not difficult to find and have been abundantly reported (Prins 1989; Wilson \& Macleod 1991). However, though strongly indicating overgrazing, by themselves these are not proof of overgrazing; they represent states of stable degradation (sensu Prins 1989; also see Rietkerk \& Van de Koppel 1997 for a theoretical treatment of the subject). As defined by Prins $(1989$, p. 292) 'Overgrazing occurs when the consumption is at such a level that the amount of vegetation is reduced to that level where further reduction of the biomass causes a reduction both in production and harvest'. The question that has remained largely unanswered is whether such changes in vegetation cause a reduction in animal production. This has been expressed by Wilson \& Macleod (1991, p. 474) '... [It is] surprising that there is not more concrete evidence available of the effects of overgrazing on animal production as opposed to the resource base'. Our objective is to present evidence of reduced animal production resulting from high stocking densities in the little known montane agro-pastoral system in Spiti Valley. Since a reduction in animal production can be effected not just by decreased food production (overgrazing) but also by decreased per caput food availability (effected merely by high livestock numbers), we choose to call it overstocking rather than overgrazing. Are Spiti's rangelands overstocked? We address this question in the present discourse, using simple models that relate animal production and stocking density. 


\section{Methods}

Study area

The $186000 \mathrm{~km}^{2}$ of the Indian Trans-Himalaya, the rain-shadow region of the Greater Himalaya, include parts of the Tibetan Plateau and the Tibetan Marginal Mountains. The Spiti Valley $\left(31^{\circ} 35^{\prime}\right.$ to $33^{\circ} 0^{\prime}$ N $\mathrm{N}$ and $77^{\circ} 37^{\prime}$ to $78^{\circ} 35^{\prime} \mathrm{E}$; altitudinal range 3350 to $6700 \mathrm{~m}$ ) in the Trans-Himalayan Lahaul and Spiti District spans an area of over $12000 \mathrm{~km}^{2}$ in the catchment of the river Spiti. The Greater Himalaya to the south, Ladakh to the north and Tibet to the east flank the region. The region is characterized by low precipitation, a short growing season, low primary productivity, and high stocking density (Mishra 2000). The livestock assemblage in Spiti includes yaks (Bos grunniens), cattle, cattle-yak hybrids, horses, donkeys, sheep and goats. The present-day SinoTibetan speaking inhabitants are thought to have occupied the region around the beginning of the first millennium $\mathrm{BC}$ (Handa 1994). Buddhism was introduced in the region in the 8 th century AD. The present local human population is entirely Buddhist. The local inhabitants are agro-pastoral, though in some villages the men also work as guides for trekking tourists and mountaineers. Livestock is owned by individual families whereas the grazing land is common to the village with equal access. The climate in Spiti is arid, with most of the precipitation in the form of snow. Temperatures range between 0 to $30^{\circ} \mathrm{C}$ in summer and -30 to $3^{\circ} \mathrm{C}$ in winter.

The steppe rangeland vegetation is characterized by the absence of tree layer. Shrub layer is largely formed by Caragana, and to a smaller extent by Lonicera, Rosa and Potentilla species. The vegetation cover is generally sparse and rarely exceeds a height of $1 \mathrm{~m}$. Several species of herbs and graminoids such as Festuca, Poa, Stipa and sedges constitute the forage biomass. The extant wild herbivores in Spiti are the bharal, ibex, and hare (Lepus oiostolus).

\section{Modelling animal production}

The assumption that overstocking can occur implies that (1) at the level of the individual animal, production should be a function of stocking density, and (2) at the level of the landscape, there should be an 'optimal' stocking density at which total herd production can be maximized. The first question to be answered then is whether or not animal production in Spiti's rangelands is related to stocking density. Animal production can be measured in different units such as weight gain per day, annual wool production, etc. (Donnelly et al. 1983, 1985). In pastoral production systems in general, $75 \%$ of the calories come from milk, and only 25\% from meat (Prins 1989). Since milk production is directly related to fecundity, the latter can also be used as a unit for measuring pastoral production.

We compared livestock performance between two adjoining rangelands differing in stocking density over three successive years (1998 to 2000). Each spring (early May), we conducted an age/sex specific census of all the livestock grazing in these two rangelands, and obtained the stocking density (in terms of biomass) for each of them. In calculating the values of stocking density, we have considered all individuals of all livestock species grazing in these two respective rangelands. This was done because all species of livestock in Spiti largely use the same resource, graminoids (C. Mishra, unpublished data 2001). Using goat and sheep as samples (their higher population enabled statistical analysis), we then calculated the average proportion of adult females that were accompanied by kids or lambs. This ratio (kid or lambs: adult female) was used as an index of livestock performance (henceforth referred to as fecundity). Since most births in goat and sheep in the region are confined to winter months (especially February-March), we believe that the ratio gives a good approximation of the annual fecundity per female.

The second question that needs to be addressed now is whether or not we can estimate an 'optimal' stocking density that would maximize herd production (fecundity) in these rangelands. The answer to this question depends upon the nature of the relationship between fecundity and stocking density. Both linear and non-linear curves have been reported for herbivores (see Crawley 1983). For simplicity, we assume that the relationship is linear. Using simple linear and quadratic models, we calculated the 'optimal' stocking density (Jones \& Sandland 1974; Wilson \& Macleod 1991).

Fecundity $\left(F_{i}\right)$ of individual females can be represented by the linear equation:

$$
F_{i}=F_{\max }-m S
$$

where $F_{\text {max }}=$ maximum annual fecundity per female, $m=$ incremental change in fecundity with change in stocking density, and $S=$ biomass density of livestock.

It now becomes possible to model the total production (fecundity) of the entire population at the landscape (rangeland) level $\left(F_{t}\right)$. This can be done using the quadratic equation (see Fig. 1):

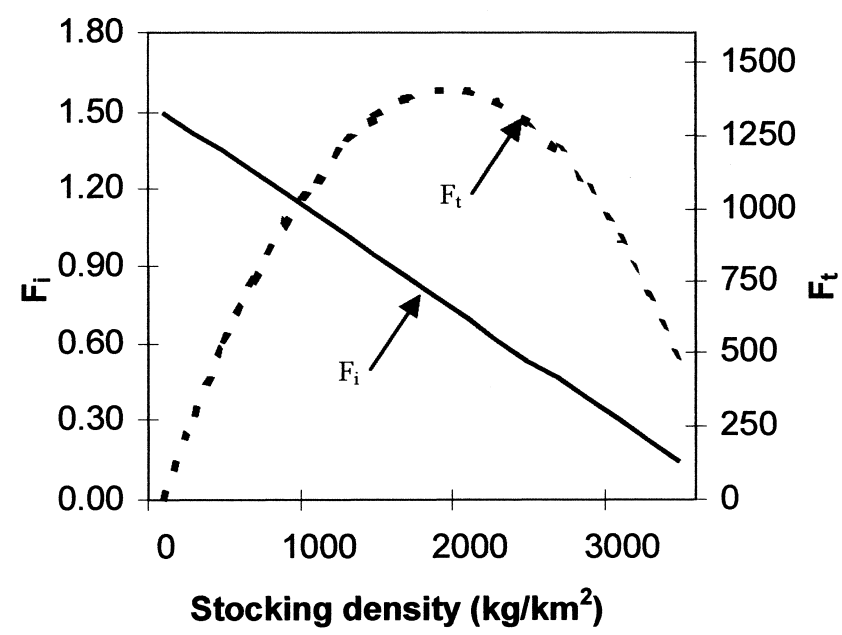

Figure 1 Fecundity $\left(F_{i}\right)$ and total herd production $\left(F_{t}\right)$ of adult female goat and sheep modelled as a function of livestock biomass density in Spiti, Indian Trans-Himalaya. 


$$
F_{t}=F_{\max } S-m S^{2}
$$

where $F_{t}=$ population fecundity or herd production per $\mathrm{km}^{2}$ of rangeland.

The vertex of this curve represents the 'optimal' biomass density $\left(S_{o p}\right)$ at which $F_{t}$ will be maximized, and can be calculated as $F_{\text {max }}^{o p} / 2 m$ (Wilson \& Macleod 1991). It is obvious, by virtue of the quadratic model (Eq. 2) that $F_{t}$ will decrease on either side of $S_{o p}$ (Fig. 1). In other words, $F_{t}$ will be lower than its value at the optimal stocking density not only when $S>S_{o p}$, but also when $S<S_{o p}$. However, these represent two very different situations. In the former case the reduction in $F_{t}$ can be ascribed to overstocking, while in the latter, the relatively lower number of females, despite their higher individual fecundity $\left(F_{i}\right)$, are not able to match the total herd production $\left(F_{t}\right)$ at $S_{o p}$. Thus, overstocking can be assumed in situations where $S>S_{o p}$.

In calculating the biomass densities, we have excluded horses and yaks that range free for most of the year and often graze in pastures far away from the villages. An age and sex specific census yielded the livestock population of the 40 villages. The number of animals belonging to each age-sex class (male or female adult, sub-adult, or young) was multiplied by the respective mean body weight, and summed to get the total biomass for each village. This was then divided by the total rangeland area owned by the village (obtained from archival records; see Mishra 1997 for details of sources) to get an estimate of biomass density.

\section{Results}

Fecundity showed a negative relationship with stocking density, with animal production being better in the rangeland with lower stocking density over all the three years (Table 1, Fig. 2). In the year 2000, there was exceptionally high mortality of goat kids, possibly because of a disease, and therefore the data of 2000 were not used.

Table 1 Relationship between animal performance and stocking density in two rangelands in Spiti, Indian TransHimalaya. The ratio between the number of young and adult females is used as an index of performance (fecundity). In the year 2000, there was exceptionally high mortality of goat kids possibly because of a disease, and therefore the data not used.

\begin{tabular}{llll}
\hline \hline Year & $\begin{array}{l}\text { Stocking density } \\
\left(\mathrm{kg} / \mathrm{km}^{2}\right)\end{array}$ & \multicolumn{2}{c}{$\begin{array}{c}\text { Fecundity } \\
\text { (kids or lambs/adult female })\end{array}$} \\
\cline { 3 - 4 } & & Goat & Sheep \\
\hline 1998 & 1327 & 1.45 & 1.33 \\
& 2567 & 0.40 & 0.43 \\
1999 & 1131 & 0.85 & 0.59 \\
& 2269 & 0.51 & 0.43 \\
2000 & 1241 & - & 1.15 \\
& 2700 & - & 0.8 \\
\hline \hline
\end{tabular}

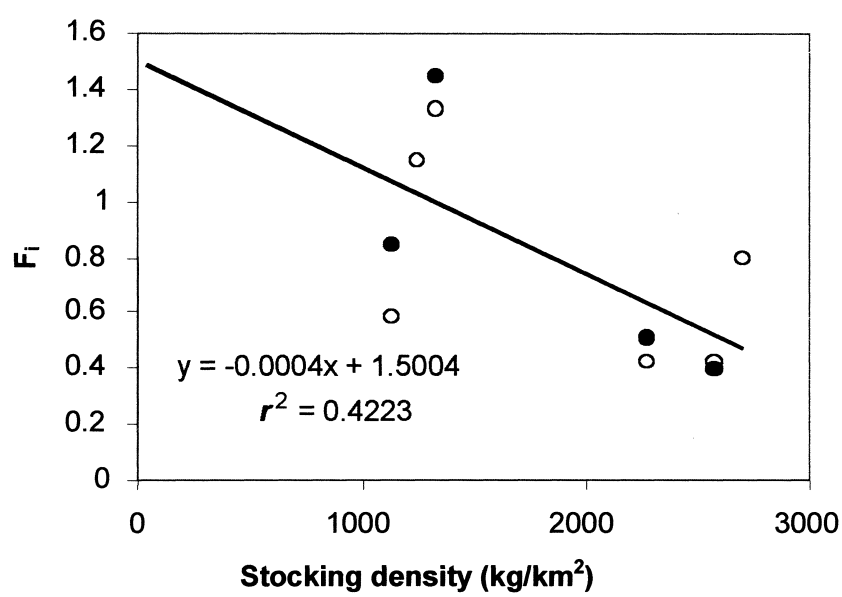

Figure 2 Fecundity $\left(F_{\mathrm{i}}\right)$ of adult female goat $(\bullet)$ and sheep (○) regressed on livestock biomass density in Spiti, Indian Trans-Himalaya. $\mathrm{y}=-0.0004 \mathrm{x}+1.5004 ; r^{2}=0.422$.

The data from Table 1 were used to calculate the incremental change in fecundity with change in stocking density $(m)$, and the maximum annual fecundity per female $\left(F_{\text {max }}\right)$. A least squares regression between $F_{i}$ and $S$ was performed which yielded values of $m=4.0 \times 10^{-4}$ and $F_{\text {max }}=5004\left(r^{2}\right.$ $=0.42 ; p<0.05$ ).

The relationship between the total herd production per $\mathrm{km}^{2}$ of rangeland $\left(F_{t}\right)$ and stocking density is given in Figure 1. The optimal stocking density $\left(S_{o p}\right)$ at which $F_{t}$ will be maximized for the rangelands of Spiti is $1876 \mathrm{~kg} / \mathrm{km}^{2}$.

We finally examined the biomass density in Spiti's rangelands in order to assess what proportion of them are overstocked. Figure 3 depicts the biomass density in rangelands belonging to 40 of Spiti's $c$. 60 villages in relation to $S_{o p}$. Only seven of the examined villages had biomass densities lower than $S_{o p}$, and only 11 that had biomass densities within $500 \mathrm{~kg} / \mathrm{km}^{2}$ of $S_{o p}$ (Fig. 3). The analysis therefore suggests that over $83 \%$ of Spiti's rangelands may be overstocked, i.e., grazed at intensities much higher than is biologically optimal.

\section{Discussion}

\section{Relationship between fecundity and stocking density}

The relationship between fecundity and stocking density was described using a linear function in order to keep the analyses simple. Indeed, a consequence of doing so is that a stocking density of $c .3750 \mathrm{~kg} / \mathrm{km}^{2}$ yields an $F_{i}$ value of zero (and subsequently negative values) which is certainly not true (see Figs. 1 and 2). We realize that ideally, an asymptotic function would be a better representation of reality, but we chose a linear function out of a desire for simplicity. Furthermore, the regression model explains only $42 \%$ of the observed variation in fecundity. This is because other factors such as precipitation (snowfall) are also important determinants of plant production and consequently seem to cause annual variation in animal production in Spiti. Perhaps a significant proportion 


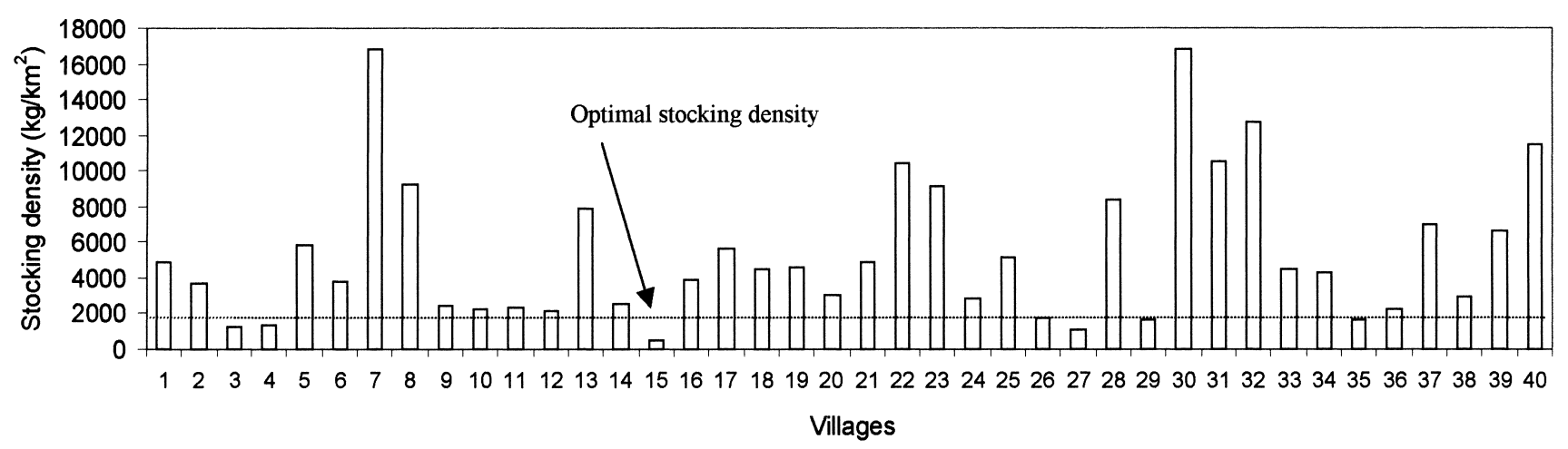

Figure 3 Livestock biomass density in rangelands of 40 villages of Spiti, Indian trans-Himalaya. The hatched line represents the optimal stocking density $\left(S_{o p}\right)$ at which herd production is maximized. Species that are free ranging for most of the year (horse and yak) are not included. Villages, corresponding to their numbers, are as follows: 1 Chichim; 2 Chichong; 3 Chidang; 4 Gete; 5 Guling; 6 Hal; 7 Hansa; 8 Hurling; 9 Kaa; 10 Kaza; 11 Kee; 12 Khar; 13 Khurik; 14 Kibber; 15 Kibri; 16 Kungri; 17 Kyomo; 18 Kyoto; 19 Langza; 20 Lara; 21 Lari; 22 Lidang; 23 Lossar; 24 Mane Kongma; 25 Mane Yongma; 26 Mikim; 27 Morang; 28 Mud; 29 Pangmo; 30 Phukchung; 31 Poh; 32 Quling; 33 Rangrik; 34 Sagnam; 35 Shego; 36 Sumling; 37 Tabo; 38 Tangti Kongma; 39 Tangti Yongma; 40 Teling.

of the unexplained variation in animal production in our data could be explained by annual variation in snowfall. However, reliable climatic data are presently lacking for the region.

\section{Causes of overstocking}

It may be assumed that the local human communities know best how to manage their land, a knowledge that has been accumulated over generations of experience. Yet, why should Spitians maintain livestock holdings so large as to compromise their own production output as indicated in the present analysis? Socio-economic changes, especially in the late 1980s and early 1990s, have resulted in an escalation of livestock population, and seem to have contributed to the currently high levels of overstocking (Mishra 2000). However, the tendency to overstock is attributable to several other causes. Being an agro-pastoral system as against a purely pastoral one, maximizing milk or meat production is not the only objective of livestock rearing in Spiti. Livestock are also needed for ploughing fields (yak and $d z o$ ), as draught animals (donkey), and for producing dung used as manure and fuel (all species). Furthermore, high levels of livestock loss to wild predators (estimated at $12 \%$ annual loss of the livestock population in some villages; Mishra 1997) may mean that a relatively larger livestock holding is required to maintain herd constancy at the family level. It is also possible that with individual ownership of livestock holdings and communal ownership of the grazing land, Spiti is witnessing a classic case of the tragedy of the commons.

\section{The implications}

The entire Spiti Valley, including the area within its wildlife reserves, is grazed by livestock (C. Mishra, personal observation 1995-2000). Such a situation perhaps prevails over most of the Indian, as well as Tibetan, trans-Himalaya (Rodgers \& Panwar 1988; Schaller 1998). A majority of the rangelands in Spiti are overstocked, and wild herbivores (bharal, Pseudois nayaur, and ibex, Capra ibex) and livestock seem to compete for forage; heavily stocked rangelands have reduced wild herbivore density (C. Mishra, unpublished data 2001). The data presented in Figure 3 in fact include six of the 13 villages that use rangelands within Kibber Wildlife Sanctuary; rangelands belonging to four of them are overstocked. Conservation management in the Trans-Himalaya must address issues of livestock husbandry and regulation of stocking density. The density of bharal, the dominant wild herbivore, is presently about ten times lower than that of livestock in Kibber, a situation responsible for high levels of depredation of livestock by wild carnivores and their retaliatory persecution by the herders (Mishra 1997). We believe that creating wildlife reserves was only a first step towards wildlife conservation in the Trans-Himalaya. With almost the entire region being grazed at high livestock density, there are hardly any areas that could serve as a benchmark for how the pastures and associated wildlife would appear in the absence of human use. Creation of (even small) inviolate areas and managing livestock stocking density in others are urgently required as the next step. The present analysis provides for the first time, a guideline, albeit a rough one, for managing herbivore density in Trans-Himalayan rangelands.

\section{Acknowledgements}

This research was financed by Netherlands Foundation for the Advancement of Tropical Research (WOTRO), part of the Netherlands Organization for Scientific Research (NWO). We thank the Himachal Pradesh Forest Department for according permission to work in Kibber, and L. Gialson and T. Dorje for invaluable help. 


\section{References}

Crawley, M.J. (1983) Herbivory: the Dynamics of Animal-Plant Interactions. London, UK: Blackwell Scientific Publications: $437 \mathrm{pp}$.

Donnelly, J.R., Morley, F.H.W. \& McKinney, G.T. (1983) The productivity of breeding ewes grazing on Lucerne or grass and clover pastures on the tablelands of southern Australia. II. Wool production and ewe weight. Australian Fournal of Agricultural Research 34: 537-548.

Donnelly, J.R., McKinney, G.T. \& Morley, F.H.W. (1985) The productivity of breeding ewes grazing on Lucerne or grass and clover pastures on the tablelands of southern Australia. IV. Lamb growth. Australian Fournal of Agricultural Research 36: 469-481.

Handa, O.C. (1994) Tabo Monastery and Buddhism in the TransHimalaya: Thousand Years of Existence of the Tabo Chos-Khor. New Delhi, India: Indus Publishing Company: 167 pp.

Jones, R.J. \& Sandland, R.L. (1974) The relation between animal gain and stocking rate: derivation of the relation from the results of grazing trials. Fournal of Agricultural Science (Camb.) 83: $335-342$.
Mishra, C. (1997) Livestock depredation by large carnivores in the Indian Trans-Himalayas conflict perceptions and conservation prospects. Environmental Conservation 24(4): 338-343.

Mishra, C. (2000) Socioeconomic transition and wildlife conservation in the Indian Trans-Himalaya. Fournal of the Bombay Natural History Society 97(1): 25-32.

Prins, H.H.T. (1989). East African grazing lands: overgrazed or stably degraded? In: Nature Management and Sustainable Development, ed. W.D. Verwey, pp. 281-306. Amsterdam, the Netherlands: IOS.

Rietkerk, M. \& Van de Koppel, J. (1997) Alternate stable states and threshold effects semi-arid grazing systems. Oikos 79: 69-76.

Rodgers, W.A. \& Panwar, H.S. (1988) Planning a protected area network in India. Volume 1: the report. Dehradun, India: Wildlife Institute of India: $314 \mathrm{pp}$.

Schaller, G.B. (1998) Wildlife of the Tibetan-Steppe. Chicago, USA: The University of Chicago Press: 373 pp.

Wilson, A.D. \& Macleod, N.D. (1991) Overgrazing: present or absent? Fournal of Range Management 44(5): 475-482. 